\title{
ZnO-CdSe Nanoparticle Clusters as Directional Photoemitters with Tunable Wavelength
}

\author{
Jin Young Kim and Frank E. Osterloh* \\ Department of Chemistry, University of California, Davis, One Shields Avenue, Davis, California 95616
}

Received April 27, 2005; E-mail: fosterloh@ucdavis.edu

Because of their tailorable optical properties, semiconductor nanocrystals are considered key materials for applications as optical probes, ${ }^{1}$ and as components in photochemical cells, ${ }^{2}$ light emitting devices, ${ }^{3}$ and lasers. ${ }^{4-6}$ While emission and absorption energies of the nanoparticles can be adjusted with the particle sizes, ${ }^{7,8}$ the polarization of the emission can be controlled with the particle shape. ${ }^{9,10}$ For $\mathrm{ZnO}$ nanowires, it has recently been shown that the exciton emission occurs preferentially in the direction of the longer axis of the nanocrystal. ${ }^{11}$ This waveguiding effect is a result of total internal reflection of the emitted light at the microcrystal-air interface. ${ }^{11,12}$ We now found that the waveguiding effect of $\mathrm{ZnO}$ microcrystals can be exploited for directing the emission of CdSe nanoparticles by covalently linking the latter to the surface of a $\mathrm{ZnO}$ microcrystal rod. The resulting nanoparticle clusters exhibit directional photoluminescence at a wavelength that can be separately adjusted with the CdSe nanocrystal size. The ability to separately control the emission direction and wavelength of semiconducting nanoparticles should be of interest for applications of such structures in displays with enhanced contrast, in microlasers, and in photonics devices.

Unidirectional light emitters were synthesized according to Scheme 1 from rod-shaped $\mathrm{ZnO}$ microcrystals ${ }^{13}$ and TOPO coated $\mathrm{CdSe} / \mathrm{CdS}$ core/shell nanoparticles. ${ }^{16}$

\section{Scheme 1}

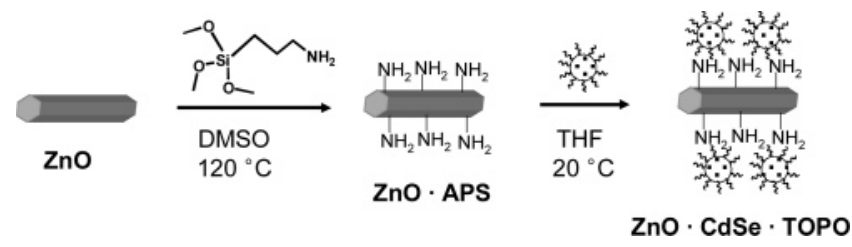

$\mathrm{ZnO}$ was chosen as a structural and optical support because of its high refractive index of $2.01,{ }^{14}$ and because as a wide band gap semiconductor $(3.2 \mathrm{eV})$ it does not absorb visible light. Reaction of the $\mathrm{ZnO}$ microrods with 3-aminopropyltrimethoxysilane (APS) produced APS-terminated $\mathrm{ZnO}$ rods, which, in a subsequent reaction with trioctylphosphineoxide (TOPO)-stabilized $\mathrm{CdSe} / \mathrm{CdS}$ coreshell nanoparticles in THF, underwent coupling to yield $\mathrm{ZnO}-$ $\mathrm{CdSe}$ clusters. In this reaction the primary amine group from APS displaces the weakly bonded TOPO from the CdS surface. SEM and TEM micrographs (Figure 1a,b) show that the clusters are composed of $\mathrm{ZnO}$ microrods that are coated with a dense $\sim 10$ nm-thick monolayer of CdSe particles. The sizes of the clusters $(6.85 \pm 1.73 \mu \mathrm{m}$ long and $0.79 \pm 0.13 \mu \mathrm{m}$ wide) are mainly determined by the sizes of the $\mathrm{ZnO}$ rods, which can be controlled by the conditions of $\mathrm{ZnO}$ synthesis. According to energy dispersive spectroscopy, the chemical composition (in mass \%) of the clusters is $1.61 \pm 0.21(\mathrm{Se}), 2.23 \pm 0.25(\mathrm{Cd}), 68.78 \pm 0.47(\mathrm{Zn}), 20.49 \pm$ $0.70(\mathrm{O}), 6.02 \pm 0.61(\mathrm{C})$, and $0.89 \pm 0.07(\mathrm{Si})$. The relatively high carbon content indicates that the $\mathrm{CdSe} / \mathrm{CdS}$ particles are partially coated with TOPO.

10152 - J. AM. CHEM. SOC. 2005, 127, 10152-10153

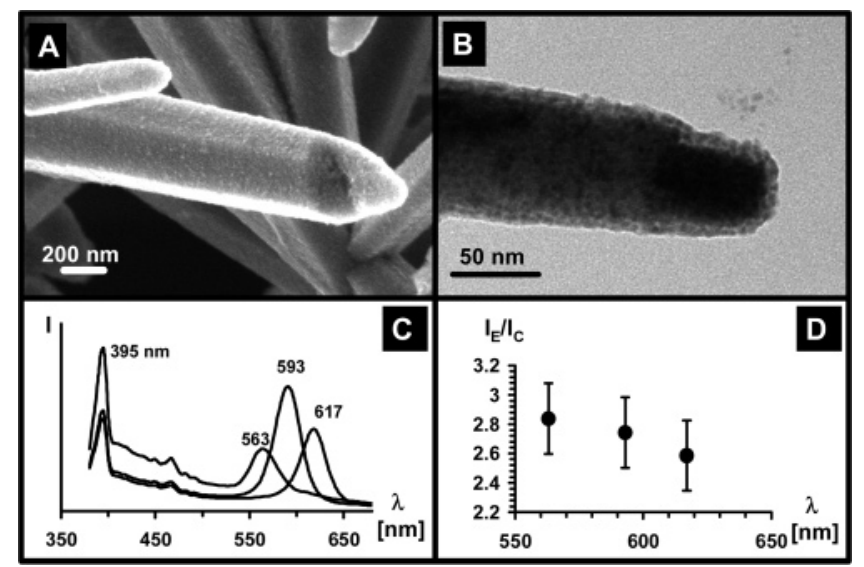

Figure 1. (A,B) SEM and TEM images of $\mathrm{ZnO}-\mathrm{CdSe}$ clusters. A monolayer of CdSe particles is noticeable. (C) Fluorescence spectra of $\mathrm{ZnO}-\mathrm{CdSe}$ clusters in chloroform $\left(\lambda_{\mathrm{ex}}=350 \mathrm{~nm}\right)$. (D) Plot of directional emission ratio versus emission wavelength.

Despite a relatively low calculated CdSe volume fraction $(2.73 \%)$, the clusters strongly emit in the visible after excitation with visible light $<550 \mathrm{~nm}$ (Figure 1c). Depending on the size of the CdSe nanocrystals $(2.1-4.0 \mathrm{~nm})$, the emission can be adjusted from yellow $(563 \mathrm{~nm})$ and orange $(593 \mathrm{~nm})$ to red $(617 \mathrm{~nm})$. When excited in the UV, the fluorescence spectrum of the particles also contains an emission feature at $395 \mathrm{~nm}$ corresponding to the band gap emissions of $\mathrm{ZnO} .{ }^{11}$ No defect emission of $\mathrm{ZnO}$ (normally at $510 \mathrm{~nm}$ ) is observed. The CdSe emission quantum yield of the clusters is comparable to that of the free CdSe quantum dots in chloroform. The fact that there is little interaction between the two semiconductors might be due to the spatial separation between $\mathrm{ZnO}$ and CdSe $(\sim 1.0 \mathrm{~nm})$, which is enforced by the APS linker.

Wide field fluorescence micrographs of $\mathrm{ZnO}-\mathrm{CdSe}$ clusters emitting yellow, orange, and red are presented in Figure $2 \mathrm{a}-\mathrm{c}$. All clusters appear dark in the center and light at the ends, which indicates that the emission occurs predominantly at the rod ends. This effect is strongest for clusters that are not in direct contact with the Si substrate (i.e., for clusters that are supported by other clusters). The mechanism for the observed directional light emission probably involves trapping of light from the photoexcited CdSe sites in the $\mathrm{ZnO}$ rods. Inside the optically dense $\mathrm{ZnO}$ rods the light is guided by total internal reflection at the $\mathrm{ZnO}-$ air interface. Using the indices of refraction of 2.01 and 1.00 for $\mathrm{ZnO}$ and air, respectively, Snell's law predicts $30^{\circ}$ as the critical angle for total internal reflection. When the clusters are immersed in a medium with higher index of refraction (e.g., microscopy oil with $n=1.59$ ), the directional emission is greatly diminished (Figure 2d). This confirms internal reflection as the mechanism for uniaxial light emission in these structures. To correlate the optical anisotropy of the clusters with their structural features, it is useful to calculate a ratio $I_{\mathrm{E}} / I_{\mathrm{C}}$ from the emission intensities of rod ends $\left(I_{\mathrm{E}}\right)$ and rod 

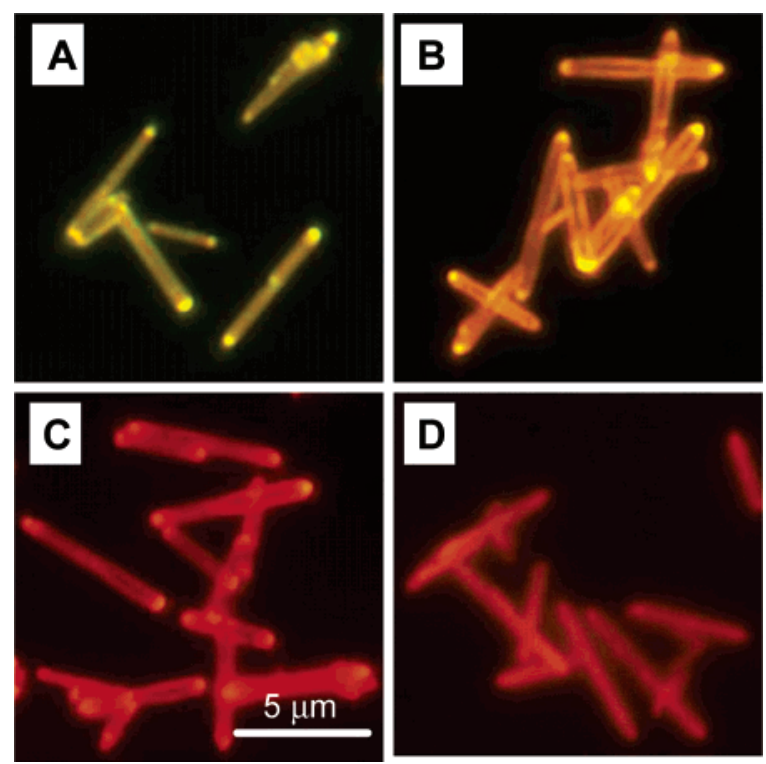

Figure 2. Fluorescence micrographs of $\mathrm{ZnO}-\mathrm{CdSe}$ clusters on a Si wafer in air $(\mathrm{A}-\mathrm{C})$ and in hydrocarbon oil with $n=1.59$ (D).

centers $\left(I_{\mathrm{C}}\right)$, respectively, and to compare this "directional emission" ratio for different microrods. Surprisingly, the analysis (Supporting Information) shows that $I_{\mathrm{E}} / I_{\mathrm{C}}$ (mean value $2.72 \pm 0.45$ ) does not depend on either the thicknesses $(0.48-1.06 \mu \mathrm{m})$ or the lengths $(3.2-10.2 \mu \mathrm{m})$ of the clusters. This suggests that waveguiding in these structures is limited by scattering losses at the cluster surfaces. These losses are significant because of the rough surface structure of the clusters and because of the great refractive index $(n=2.45)$ of the $\mathrm{CdSe} / \mathrm{CdS}$ nanoparticles. As Figure 1d shows, there is also a weak inverse dependence of the directional emission ratio on the emission wavelengths $\left(\lambda_{\mathrm{em}}\right)$ of the microstructures. This indicates that, as $\lambda_{\mathrm{em}}$ becomes larger, the light emitted by the CdSe nanocrystals is increasingly coupled to the Eigenmodes of the hexagonal $\mathrm{ZnO}$ rods, which act as optical cavities. The transition from multimode $(W \gg 1)$ to single mode $(W \ll 1)$ waveguiding is also expected from the waveguide parameter $W=\left(2 \pi \delta / \lambda_{\mathrm{em}}\right)\left(n_{\mathrm{ZnO}}{ }^{2}\right.$ $-n_{\text {air }}^{2}$ ) for these structures (see comments in Supporting Information), which lies between 3.49 and 3.67 (for mean radius $\delta=395$ $\mathrm{nm}$, refractive index $n=2.01$, emission wavelength $\lambda_{\mathrm{em}}=560$ $620 \mathrm{~nm}) .{ }^{15}$ In terms of their ability to guide light of variable wavelengths, the $\mathrm{ZnO}-\mathrm{CdSe}$ clusters thus represent the lower size limit.

In conclusion, we have demonstrated that directional emission of CdSe quantum dots can be achieved by chemical linkage of CdSe nanocrystals to $\mathrm{ZnO}$ microrods, which act as optical waveguides. In terms of their anisotropic optical properties, the $\mathrm{ZnO}-\mathrm{CdSe}$ clusters resemble $\mathrm{ZnO}$ nanowires, for which a similar waveguiding mechanism has been postulated. The difference is that the light emitted by $\mathrm{ZnO}-\mathrm{CdSe}$ is generated by the CdSe nanoparticles and not by the $\mathrm{ZnO}$ rods, and that by changing the CdSe nanocrystal size, the emission wavelength of these structures can be adjusted. The described clusters are different from CdSe nanorods ${ }^{9}$ in that they lack a polarization of the emitted light. In the latter structures, the emission is polarized due to a preferred orientation of the oscillating electrical dipole.

Our results suggest that the emission of other semiconductor nanocrystals can be similarly adjusted in three dimensions by combining them with microcrystals of other optically dense materials. The modular character of the nanoparticle cluster assembly approach thus presents an advantage over direct synthesis of emissive nanostructures, which is often limited to specific materials and conditions. The versatility and the scalability of the approach should lead to improved applications of emissive nanostructures in materials and devices.

Acknowledgment. Jin Young Kim thanks the Tyco Electronics Corporation for a summer fellowship. This work was supported by startup funds of the University of California at Davis and by NSF Grant No. CTS-0427418.

Supporting Information Available: Full experimental details and SEM and TEM images of $\mathrm{ZnO}-\mathrm{CdSe}$ clusters and $\mathrm{ZnO}$ rods, emission spectra of TOPO-supported CdSe nanoparticles, and plots of the dependence of the directional emission ratio on cluster length and thickness. This material is available free of charge via the Internet at http://pubs.acs.org.

\section{References}

(1) Bruchez, M.; Moronne, M.; Gin, P.; Weiss, S.; Alivisatos, A. P. Science 1998, 281, 2013-2016.

(2) Huynh, W. U.; Peng, X.; Alivisatos, A. P. Adv. Mater. 1999, 11, 923927

(3) Colvin, V. L.; Schlamp, M. C.; Alivisatos, A. P. Nature 1994, 370, 354357.

(4) Klimov, V. I.; Mikhailovsky, A. A.; Xu, S.; Malko, A.; Hollingsworth, J. A.; Leatherdale, C. A.; Eisler, H. J.; Bawendi, M. G. Science 2000, 290, 314-317.

(5) Eisler, H. J.; Sundar, V. C.; Bawendi, M. G.; Walsh, M.; Smith, H. I.; Klimov, V. Appl. Phys. Lett. 2002, 80, 4614-4616.

(6) Cha, J. N.; Bartl, M. H.; Wong, M. S.; Popitsch, A.; Deming, T. J.; Stucky, G. D. Nano Lett. 2003, 3, 907-911.

(7) Brus, L. Appl. Phys. A 1991, 53, 465-474.

(8) Alivisatos, A. J. Phys. Chem. B 1996, 100, 13226-13239.

(9) Hu, J. T.; Li, L. S.; Yang, W. D.; Manna, L.; Wang, L. W.; Alivisatos, A. P. Science 2001, 292, 2060-2063.

(10) Wang, J. F.; Gudiksen, M. S.; Duan, X. F.; Cui, Y.; Lieber, C. M. Science 2001, 293, 1455-1457.

(11) Johnson, J. C.; Yan, H. Q.; Yang, P. D.; Saykally, R. J. J. Phys. Chem B 2003, 107, 8816-8828

(12) Yan, H.; Johnson, J.; Law, M.; He, R.; Knutsen, K.; McKinney, J.; Pham, J.; Saykally, R.; Yang, P. Adv. Mater. 2003, 15, 1907-1911.

(13) McBride, R. A.; Kelly, J. M.; McCormack, D. E. J. Mater. Chem. 2003 $13,1196-1201$

(14) Jellison, G. E.; Boatner, L. A. Phys. Rev. B 1998, 58, 3586-3589

(15) Snyder, A. W.; Love, J. D. Optical Waveguide Theory; Chapman and Hall: London; New York, 1983; pp viii, 734.

(16) Mekis, I.; Talapin, D. V.; Kornowski, A.; Haase, M.; Weller, H. J. Phys. Chem. B 2003, 107, 7454-7462.

JA052735F 